\title{
Monográfico sobre Comunicación e investigación cualitativa
}

institucional.us.es/ambitos/

Julieti Oliveira

Coordinadora del monográfico

La edición de inverno 2015/2016 de la revista Ámbitos presenta un monográfico especial que guarda relación con un trabajo acordado entre la revista y los organizadores portugueses y brasileños del $4^{\circ}$ Congresso Ibero-Americano em Investigação Qualitativa (CIAIQ2015), celebrado en agosto de 2015 en

la Universidade de Tiradentes, ubicada en la ciudad brasileña de Aracaju. Se trata de la cuarta edición de un Congreso de comunicación que, organizado por entidades de Portugal y de Brasil, reúne a participantes de todo el mundo para la presentación de artículos científicos originales que se ajusten a la temática acordada para el mismo.

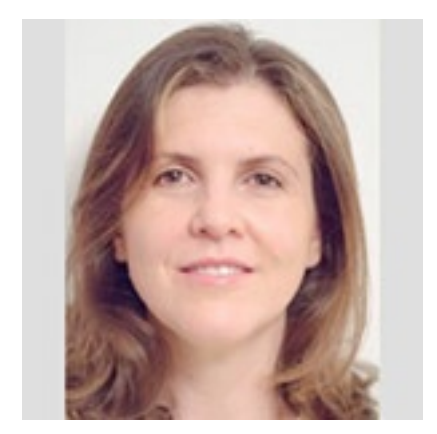

La temática del Congreso gira en torno a la investigación cualitativa en comunicación y, sobre ello, los artículos que a continuación se presentan, aportan una información fundamentada y de calidad científica capaz de dignificar este monográfico. Precisamente, una de sus características es la riqueza lingüística y cultural que en él se refleja, ya que recoge artículos escritos en portugués y español, procedentes de países como España, Italia, Chile, Argentina, Brasil o Portugal.

En primer lugar, el artículo titulado Representaciones de la memoria religiosa en el movimiento de los focolares, de la Dra. Augustina Adela Zaros (Universidad de Padova, Italia), estrechamente ligado a la comunicación interpersonal e intergrupal, trata sobre la transmisión religiosa en las familias y miembros del Movimiento de los Focolares. La autora analiza la religión desde la perspectiva de la memoria en la reinterpretación de cada generación, como herramienta de continuidad entre el pasado y el presente en una línea de creencias. De esta manera, el texto presenta una descripción sobre el movimiento religioso desde un método de observación participante aplicado en dos ciudades del movimiento religioso en Italia y en Argentina. El objetivo principal es conocer la dinámica del movimiento, articulando su dimensión transnacional con lo local de la participación de sus miembros.

El siguiente articulo Ciudadania, subcidadania e opinião pública: uma leitura critica das mídias brasileiras e portuguesas, procedente de Brasil, pertenece a Simone Antoniaci Tuzzo, Doctora en Comunicación por la Universidad Federal de Rio de Janeiro. En su trabajo, realiza un análisis crítico sobre el significado que se da en los medios portugueses y brasileños al concepto de ciudadanía, teniendo en cuenta la influencia que poseen los medios de comunicación en la construcción social del término. Se trata de un punto de reflexión para el entendimiento crítico que se forma en torno a las diferencias que ofrece el concepto de "ciudadano" en Brasil, un país en desarrollo, y en Portugal, un país desarrollado. La autora aborda el trabajo tras una selección de periódicos impresos y electrónicos brasileños y portugueses durante el año de 2014. La investigación se centra en examinar el significado social que genera la palabra ciudadanía hablada en un mismo idioma, pero en países con condiciones sociales diferentes.

Por su parte, la investigación titulada: Construcción del concepto audiencia como objeto de estudio en la modernidad contemporánea. Una aproximación teórica, epistemológica y metodológica con foco en la tv pública, es un trabajo conjunto del sociólogo José Henrique Fernández y de la doctora en Sociología Ana Marta Martínez, ambos procedentes de la Universidad de la Republica, Montevideo, Uruguay. Su trabajo presenta una discusión sobre los métodos de investigación aplicados en el estudio de las audiencias con foco en la televisión pública. El estudio parte de la necesidad de producir conocimiento original teniendo en cuenta el marco actual de la modernidad contemporánea. A ello se suma la necesidad de que los actores responsables de la televisión pública uruguaya cuenten con un nuevo tipo de conocimiento que les permita programar e 
interactuar con las audiencias desde una lógica de generación de valor público. El artículo incluye una discusión teórica y epistemológica, con la que se desarrolla un diseño metodológico concreto para investigaciones de audiencias desde un enfoque de métodos combinados.

Otro trabajo procedente de Brasil es A festa do Divino Espirito Santo em Santa Cruz de Goiás. Um universo rico de manifestações culturais. Sus autores, Liberalina Teodoro de Rezende, Sandro Dutra e Silva, Giovana Galvão Tavares, Maria Idelma Vieira D’abadia, Abadia de Lourdes da Cunha, desarrollan un análisis del patrimonio cultural imaterial de la ciudad brasileña de Santa Cruz. Para ello, aplican el método de observación y de grupo Focal participante para conocer y comprender, actitudes, opiniones y comportamientos de los habitantes relacionados a la celebración de la fiesta del Divino Espirito Santo. La fiesta tiene origen europeo y es considerada como una de las festividades más antiguas del pueblo brasileño. Entre las conclusiones del trabajo, destaca la que señala que el tradicional festejo permite a la sociedad crear y recrear sus propias manifestaciones y su propia cultura.

En el artículo Nota como exemplar textual do discurso de uma mídia corporativa, también procedente de Brasil, los autores Hélder Uzêda Castro investigador y Marta Cardoso de Andrade, ambos expertos en comunicación corporativa, examinan el discurso de una revista de comunicación interna de una de la más grandes empresas brasileñas. Para ello, han seleccionado concretamente una nota de la revista que hacía referencia a un acontecimiento importante de la actualidad, de utilidad dentro y fuera de la empresa. Para lograr los objetivos esperados, se analizó la construcción del ethos y de la situación enunciativa, así como el uso de los argumentos y de los elementos lingüísticos del discurso existente en una nota de una revista empresarial. Como aporte teórico, los autores hicieron uso de los estudios de Comunicación Organizacional, Retorica/Nueva Retorica y Análisis de discurso en su línea francesa. La investigación resalta el importante papel de la comunicación en las corporaciones y, además, destaca la importancia del conocimiento de las técnicas del discurso tanto para los profesionales de la comunicación como para los administradores de empresas, todo ello para que, en un mundo cada vez más comunicacional e persuasivo, sepan cómo llegar a sus colaboradores internos y conocer los problemas de les afecta.

Por último, en Las comunicación de la innovación de las agencias de medios. Big Data en las webs propias, procedente de la Universidad de Valencia, España, la Doctora Natalia Papi Gálvez y la publicista Raquel García-Bonal presentan un estudio en el que exploran el uso que hacen las agencias de medios españolas de las webs corporativas para comunicar servicios relacionados con la tecnología big data. Junto a ello, se evalúa el responsive design de las webs de las principales agencias y se detectan las debilidades, amenazas, fortalezas y oportunidades de su aplicación. El trabajo se realizó a través de un estudio exploratorio basado en la investigación documental de las 20 primeras agencias en España. Los autores reflexionan sobre cómo la transformación del escenario mediático afecta a la actividad de las agencias de medios. Entre sus principales conclusiones, señalan que las agencias españolas deberán encontrar fórmulas para poder aspirar a diseñar estrategias más eficaces en la sociedad digital, además de hacer un mayor esfuerzo para comunicar tales innovaciones a través de sus webs.

En términos generales, es de gran importancia para Ámbitos y para su público la aportación de conocimiento de este trabajo en conjunto con la organización del CIAIQ2015. El enriquecimiento cultural que aporta la divulgación de artículos de autores de diferentes nacionalidades, cultura e idiomas contribuye a ofrecer diferentes puntos de vista de una misma realidad ubicada en diferentes contextos. Por ello, trabajos de este tipo son fundamentales para promover la integración y el desarrollo entre los investigadores, ya que les permiten divulgar y sacar a la luz estudios de gran calidad para el ámbito de la comunicación

Ámbitos. Revista Internacional de Comunicación, n.31, edición de invierno, 2016. 